\title{
Trends in smoking and smokeless tobacco use among Danish Adolescents, 1997-2014
}

\author{
Janne S. Tolstrup ${ }^{1}$, Veronica S. C. Pisinger', Kia K. Egan' ${ }^{1}$ Anne I. Christensen'
}

\begin{abstract}
INTRODUCTION High rates of smoking among adolescents remain a public health concern. This study investigates smoking behavior and use of smokeless tobacco among Danish high-school students and assesses how smoking and use of smokeless tobacco cluster in schools and school classes. We estimate the trend in cigarette smoking from 1997 to 2014.

METHODS We used data on 70243 students, from 3214 school classes in 119 high schools, who participated in the Danish National Youth Study from 2014. We had information on $87 \%$ of all Danish high schools and $85 \%$ of eligible students. We also used data from 1997 on 26644 high-school students from a similar data set to assess the chronological trend in smoking. We calculated prevalences and intraclass correlation coefficients (ICCs) to estimate between-school and between-school class clustering in smoking and use of smokeless tobacco.

RESULTS In all, $14 \%$ of boys and $11 \%$ of girls were daily smokers. A large fraction of the variation in smoking and the use of smokeless tobacco was attributable to the school and school-class level (ICC of 0.19, 0.12, 0.16 and 0.27 , for daily smoking, waterpipe smoking, use of electronic cigarettes and snuff/chewing tobacco, respectively). Daily smoking decreased from 15\% in 1997 to $12 \%$ in 2014, while more students were occasional smokers in 2014 than in 1997 (30\% vs 18\%).

CONCLUSIONS The prevalence of smoking was high among Danish high-school students and had changed little since 1997. The school and class environment accounted for a large part of the variation in smoking behavior.
\end{abstract}

\section{INTRODUCTION}

Despite the solid evidence of smoking's addictive properties and the comprehensive associated harms, high rates of smoking among adolescents remain a global public health concern. In 2015, 18 countries in western and central Europe had a smoking prevalence among girls, aged between 15 and 19 years, higher than $15 \%$, and only three countries worldwide had significant decreases in adolescent smoking in the period from 2005 to $2015^{1}$.

During the last decade, alternative smoke and smokeless products have become available and are being increasingly used; most popular are electronic cigarettes (e-cigarettes) and waterpipe,
AFFILIATION

1 National Institute of Public Health, University of Southern Denmark, Copenhagen, Denmark

CORRESPONDENCE TO Janne S. Tolstrup. National Institute of Public Health, University of Southern Denmark, Studiestræde 6, Copenhagen

1455, Denmark.

E-mail:jst@niph.dk

KEYWORDS

smoking, youth, youth smoking, smokeless tobacco

Received: 12 October 2017

Revised: 5 March 2018

Accepted: 6 March 2018 
has previously demonstrated the importance of the school on behavior such as smoking. Although the amount of between-school variability as quantified in previous studies seems modest (3-11\%), at population level it represents a substantial amount that could be addressed by school-based interventions, resulting in a potentially large impact ${ }^{14}$. Nevertheless, research on the importance of school environment in relation to comorbid substance-use is scarce and studies on the impact of the school class, to our knowledge, are non-existent. Clustering of tobacco use at the school class level is interesting, but while school clustering may reflect clustering of other local conditions such as neighbourhood socio-economy, variation in the influence of school classes represents factors associated with social dynamics and norms between students as well as between students and teachers. By investigating the impact of the school class, we attempt to answer the question of what it means to a young person's smoking behavior to be in one class compared to another within the same school.

In principle, a tobacco endgame can become reality through a combination of two approaches: encouraging current smokers to quit and preventing others, most importantly children and adolescents, from initiating smoking. Virtually all daily cigarette smokers begin before the age of 18 years, a time period where the frontal cortical areas of the brain, responsible for cognitive control over behavior, are not fully developed. Consequently, a deliberate decision to smoke is unlikely ${ }^{15-17}$. Furthermore, the adolescent brain may be especially sensitive to nicotine, thus early exposure may directly increase the risk for dependence ${ }^{18}$. Monitoring closely smoking behavior among adolescents and having detailed knowledge about factors associated with smoking initiation is therefore important. Characterization of key determinants and trends in tobacco use is essential to develop and maintain programs aiming at preventing and reducing smoking in adolescents.

The aim of this study was to investigate the use of tobacco in Danish high-school students. More specifically, we aimed to: 1) provide detailed information on student use of cigarettes, e-cigarettes, waterpipe and snuff/chewing tobacco and their wish to quit smoking; 2) quantify class-level and school-level effects on smoking and use of smokeless tobacco; and 3) assess the trend in cigarette smoking from 1997 to 2014.

\section{METHODS}

\section{The Danish National Youth Study 2014}

Data comes from the Danish National Youth Study 2014, a national survey of 75853 high-school and vocational-school students in 2014. A thorough description of the study methods and population characteristics of the Danish National Youth Study 2014 have been given elsewhere ${ }^{19}$. The Danish National Youth Study 2014 was conducted with the aim of investigating health, health behavior and mental health among young people in secondary education in Denmark. The present study only included high-school students $(n=70674)$.

Data were collected from August to November 2014. Teachers gave students a code to access the electronic survey. Students answered the questionnaire consisting of 380 questions in class during one or two lessons lasting 45 minutes each. In total, 119 of the 137 high schools participated (87\%). All students in all grades were invited to participate in the survey $(n=85835)$ and the proportion of students who participated was $85 \%$ (Figure 1).

\section{Figure 1. Overview of the Danish National Youth} Study 2014

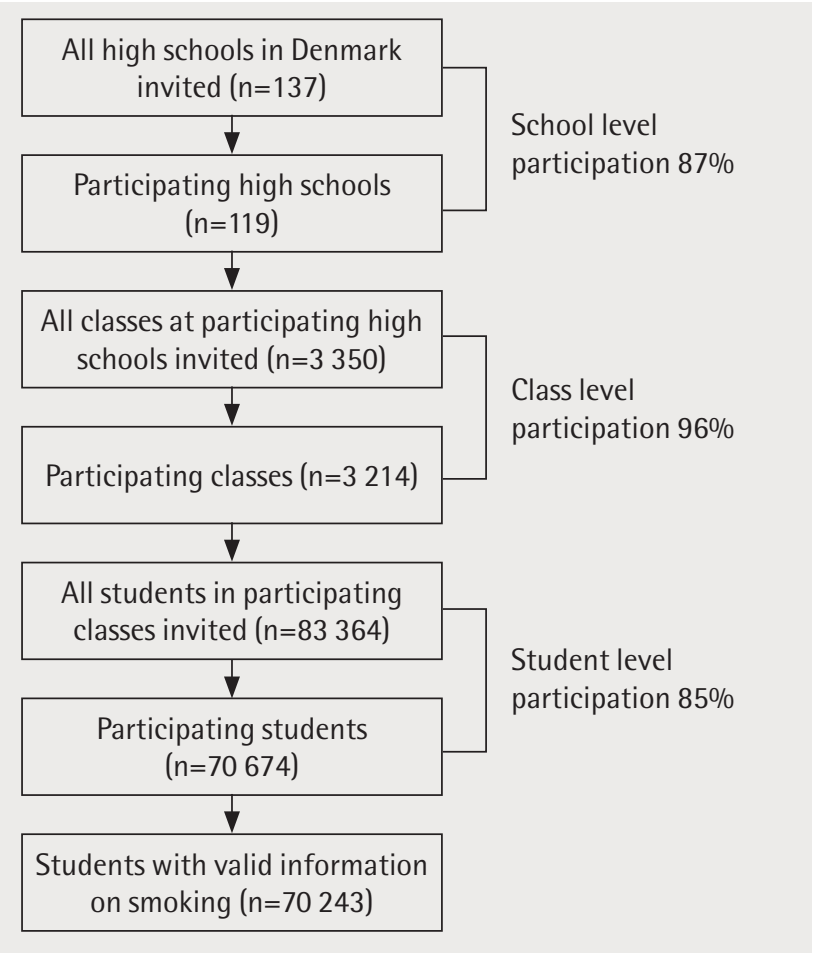


High school allows students to qualify for higher education, most importantly university, and comprises two study programmes: a three-year standard program (92\%), and a two-year compact program $(8 \%)$. Participants with missing data on smoking status $(n=431)$ were excluded from the study, resulting in a study population of 70243 students.

Smoking prevalence was compared to an equivalent survey of $1997(\mathrm{n}=24644)^{20}$. The two surveys had a fairly even gender distribution ( $39 \%$ boys), though the 1997 survey included a larger proportion of first year students (50\% in 1997 compared to $37 \%$ in 2014 ), and a larger proportion of students in the twoyear compact program (12\% in 1997 vs $8 \%$ in 2014); this was accounted for in the comparisons.

\section{Measures}

Smoking status

Students were asked what statement best described their smoking status: 'I smoke every day', 'I smoke at least once a week', 'I smoke occasionally (e.g. at parties)', 'I rarely smoke', and 'I never smoke'. Students that answered 'I never smoke' were asked if they previously had smoked. Those answering 'I smoke every day' were coded as daily smokers, and those answering 'I smoke at least once a week' were coded as weekly smokers. The answers: 'I smoke occasionally (e.g. at parties)' and 'I rarely smoke' were coded as occasional smokers, and 'I never smoke' coded as never smokers, while those who had previously smoked were coded as ex-smokers.

In the 1997 survey, students were asked 'Do you smoke?' with the possible answers 'Yes, every day', 'Yes, at least weekly', 'Yes, but less often than once a week', 'Yes, but only at parties' and 'No, I do not smoke'. Those answering: 'Yes, every day' were coded as daily smokers, and 'Yes, at least weekly' were coded as weekly smokers, while the answers 'Yes, but less often than once a week' and 'Yes, but only at parties' were coded as occasional smokers. 'No, I do not smoke' were coded as non-smokers. Never smokers and ex-smokers in the 2014 study were referred to as non-smokers compared to the 1997 study.

Waterpipe, electronic cigarette and snuff/chewing tobacco use

Students were also asked if they had ever tried waterpipe, electronic cigarettes, or snuff/chewing tobacco, with the possible answers: 'No', 'Yes a few times', 'Yes, I use/smoke regularly' and 'Yes, I use/ smoke daily', separately for each type. Two types of variables were coded on the use of waterpipe, electronic cigarettes, or snuff/chewing tobacco: the first type were chosen to indicate if students had ever tried waterpipe, electronic cigarettes and snuff/ chewing tobacco; the second type were chosen to distinguish between no use, occasional use, often use and daily use.

\section{Any daily smoking}

A variable was coded to indicate if students smoked cigarettes, waterpipe or electronic cigarettes daily.

\section{Number of cigarettes}

Daily smokers were asked how many cigarettes they smoked daily. Weekly smokers were asked how many cigarettes they smoked a week.

\section{Nicotine dependence}

Nicotine dependence was measured by two items from the Fagerström Test for Nicotine Dependence ${ }^{21}$. Daily smokers were asked: 'What cigarette is the most difficult to do without?' with possible answers 'The morning cigarette' or 'Another', and 'Do you smoke when you are ill and lying in bed' with possible answers 'Yes' or 'No'. Students, who answered that the morning cigarette was the most difficult to do without, and who smoked when they were ill and lying in bed, were coded as nicotine dependent.

\section{Wish to quit smoking}

Wish to quit smoking was measured by the question: 'Do you wish to quit smoking?' with possible answers 'No', 'Yes, but not planned', 'Yes, within the next 6 months', and 'Yes, within the next month'.

\section{Other covariates}

Participants were also asked to report: 1) perceived ethnicity (Danish, Danish and other, ethnicity other than Danish); 2) cohabitation, "who do you live with?' (live alone, live with both parents, live with one parent - mother or father); 3) parental separation within the last year, "within the last year, have your parents moved apart?' (yes/no); 4) financial strains in the family within the last year, "within the last year, 
have your parents had difficulties paying the bills?' (yes/no); 5) quality of life measured by Cantril's ladder (scores 7 indicating high quality of life); and 6) school satisfaction, 'at the moment, how do you like going to school?' (very good, or good/less good, or bad).

Almost all participants in the Danish National Youth Study 2014 have been linked to their unique Personal Identification Number (CPR) (95\% of the high-school students). Participants were linked to the Danish Civil Registration System and the educational register ${ }^{22}$ to identify parents and parents' highest achieved educational level. Parents' highest achieved educational level was coded into basic schooling, high school or vocational school, and higher education.

\section{Statistical analysis}

Statistical analyses and data processing were performed using STATA 14. To test for clustering of smoking behavior in school and school classes, we used multi-level logistic regression, nesting participants within school classes $(n=3214)$ and within schools $(n=119)$, to calculate intraclasscorrelation coefficients (ICC) for school and class, for daily smoking, waterpipe use, electronic cigarette use, snuff/chewing tobacco use, and wish to quit smoking. ICG was calculated as:

School level: $\frac{\sigma_{2}^{2}}{\sigma_{2}^{2}+\sigma_{1}^{2}}$, class level: $\frac{\sigma_{3}^{2}}{\sigma_{2}^{2}+\sigma_{3}^{2}+\sigma_{1}^{2}}$, and school + class level $\frac{\sigma_{2}^{2}+\sigma_{3}^{2}}{\sigma_{2}^{2}+\sigma_{3}^{2}+\sigma_{1}^{2}}$,

where $\sigma_{2}^{2}$ is the variance between schools, $\sigma_{3}^{2}$ is the variance between classes, and $\sigma_{1}^{2}$ is the variance between students which is approximated to be $3.29^{23}$. All analyses were adjusted for age, gender and study program.

To compare smoking prevalence for 1997 and 2014, data from 1997 were weighted by the relative distribution of gender, study program, and school year, to match the distribution in 2014 as 1st graders and students who were enrolled in the two-year compact program were oversampled in 1997.

\section{RESULTS}

\section{Study population characteristics}

The total study population included 70243 high- school students (Table 1). The majority were girls $(n=61 \%)$ and the mean age was 17.9 years. The majority was of Danish origin, had parents with a higher education, lived with both parents, had no financial strains in the family, and a perceived high quality of life and high school satisfaction. A total of $12 \%$ reported daily smoking and $51 \%$ that they had never smoked. The proportion of daily smokers was higher among boys (14\%) than girls (11\%). No difference between boys and girls was observed for the proportion of never smokers ( $51 \%$ vs $52 \%$ ).

\section{Smoking behavior}

Daily smokers on average smoked 9.3 cigarettes a day

Table 1. Descriptive characteristics of the Danish National Youth Study 2014 (n=70 243)

\begin{tabular}{|c|c|c|c|}
\hline & $\begin{array}{l}\text { Total }(\%) \\
70213(100)\end{array}$ & $\begin{array}{l}\operatorname{Boys}(\%) \\
27170(39)\end{array}$ & $\begin{array}{l}\text { Girls (\%) } \\
12773(61)\end{array}$ \\
\hline \multicolumn{4}{|l|}{ Age } \\
\hline Mean years (SD) & $17.9(1.6)$ & $18.0(1.9)$ & $17.8(1.3)$ \\
\hline \multicolumn{4}{|l|}{ School year N (\%) } \\
\hline 1st & 24735 (37) & 10245 (37) & $15996(37)$ \\
\hline 2nd & $22016(35)$ & $9586(35)$ & $14821(35)$ \\
\hline $3 r d$ & $18533(28)$ & $7639(28)$ & 11956 (28) \\
\hline \multicolumn{4}{|c|}{ Perceived ethnicity* N (\%) } \\
\hline Danish & 62390 (91) & 23915 (89) & 38475 (91) \\
\hline Danish and other & $4820(7.0)$ & $2040(7.6)$ & $2780(6.6)$ \\
\hline Other than Danish & $2023(2.9)$ & 975 (3.6) & $1048(2.5)$ \\
\hline \multicolumn{4}{|c|}{ Parental education* N (\%) } \\
\hline Basic schooling & $2803(4.2)$ & 909 (3.5) & $1894(4.7)$ \\
\hline $\begin{array}{l}\text { High school or } \\
\text { vocational training }\end{array}$ & 22859 (35) & $7923(31)$ & $14936(37)$ \\
\hline Higher education & $40603(61)$ & $17009(66)$ & $23594(58)$ \\
\hline \multicolumn{4}{|l|}{ Cohabitation* N (\%) } \\
\hline $\begin{array}{l}\text { Lives with both } \\
\text { parents }\end{array}$ & 42622 (65) & $17999(66)$ & $27108(64)$ \\
\hline $\begin{array}{l}\text { Lives with one } \\
\text { parent }\end{array}$ & 19192 (29) & $7634(28)$ & $12689(30)$ \\
\hline Lives alone & $3844(5.9)$ & $1547(5.7)$ & $2588(6.1)$ \\
\hline \multicolumn{4}{|c|}{ Financial strains in the family $a^{*} \mathrm{~N}(\%)$} \\
\hline Yes & $10452(16)$ & $3334(12)$ & 7666 (18) \\
\hline No & $55590(84)$ & 23642 (88) & $34775(82)$ \\
\hline \multicolumn{4}{|c|}{ High quality of life $b^{*} N(\%)$} \\
\hline Yes & 49408 (71) & $21396(79)$ & 28408 (67) \\
\hline No & $20078(29)$ & $5860(21)$ & $14218(33)$ \\
\hline \multicolumn{4}{|c|}{ School satisfaction N (\%) } \\
\hline High & $57534(83)$ & $23068(86)$ & $34466(81)$ \\
\hline Low & $11799(17)$ & $3836(14)$ & 7963 (19) \\
\hline
\end{tabular}


and $19 \%$ of daily smokers could be characterized as heavy smokers (i.e. smoking 15 or more cigarettes daily) (Table 2). Weekly smokers on average smoked 13.6 cigarettes a week. The age of smoking initiation was lower among daily smokers (14 years) compared to weekly (15 years), occasional (15 years) and exsmokers (15 years). Among daily smokers, one in four (24\%) showed signs of nicotine dependence based on the Fagerström Test for Nicotine Dependence. Daily and weekly smokers had more experience with snuff or chewing tobacco, waterpipe and e-cigarettes than did occasional smokers, ex-smokers and never smokers. The proportion wanting to quit was higher among daily smokers (78\%) compared to weekly smokers (63\%) and occasional smokers (45\%). However, the proportion planning to quit within the next month was higher among occasional smokers
(14\%) compared to daily smokers (8.5\%) and weekly smokers $(12 \%)$.

The prevalence of daily smoking of cigarettes, waterpipe and e-cigarettes combined, increased with age among boys: for boys aged $\leqslant 16,17,18$ and 19 years, the prevalence of daily smoking was $9 \%$, $13 \%, 16 \%$ and $23 \%$, respectively (Figure 2 ). The prevalence of daily smoking also increased with age in girls, however less pronounced (Figure 2).

\section{Multilevel analysis: Variation between schools and} school classes

Table 3 displays the school-level intra-class correlations in relation to tobacco use. The ICC calculations showed that $27 \%$ of the variation in snuff/chewing tobacco use, $19 \%$ of the variation in daily smoking and $16 \%$ of the variation in electronic cigarette use could be ascribed to

Table 2. Number of cigarettes, smoking debut age, nicotine dependence, snuff/chewing tobacco use, water pipe use, electronic cigarette use, and wish to quit smoking, across smoking status

\begin{tabular}{|c|c|c|c|c|c|c|}
\hline & \multicolumn{6}{|c|}{ Smoking status } \\
\hline & $\begin{array}{l}\text { Total } \\
\text { n }=70213 \\
(100)\end{array}$ & $\begin{array}{l}\text { Daily } \\
\text { n= } 8223 \\
(12)\end{array}$ & $\begin{array}{l}\text { Weeklya } \\
\text { n } 2917 \\
(1.2)\end{array}$ & $\begin{array}{l}\text { Occasional }{ }^{\#} \\
\text { In } 20771 \\
(30)\end{array}$ & $\begin{array}{l}E T \\
\text { In } 2209 \\
(3.1)\end{array}$ & $\begin{array}{l}\text { Never n } 36 \\
113(51)\end{array}$ \\
\hline Smoking debut age in years mean (SD) & & $14(1.9)$ & $15(1.7)$ & $15(1.7)$ & $15(1.9)$ & \\
\hline \multicolumn{7}{|l|}{ Number of cigarettes } \\
\hline Daily mean (SD) & & $9.3(7.0)$ & & & & \\
\hline Weekly mean (SD) & & & $13.6(19)$ & & & \\
\hline Nicotine dependent* N (\%) & & $1935(24)$ & & & & \\
\hline \multicolumn{7}{|l|}{ Water pipe use $\mathrm{N}(\%)$} \\
\hline No & 25865 (37) & $266(3.2)$ & $171(15)$ & $3167(15)$ & 411 (19) & $21850(61)$ \\
\hline Experimental use ${ }^{\wedge}$ & 36032 (52) & $5398(66)$ & $1942(67)$ & $14373(69)$ & $1523(69)$ & $12796(36)$ \\
\hline Often use & 7667 (11) & $2387(29)$ & $766(26)$ & $3078(15)$ & $247(11)$ & $1189(3.3)$ \\
\hline Daily use & $401(0.6)$ & $164(2.0)$ & $28(1.0)$ & $92(0.4)$ & $19(0.9)$ & $98(0.3)$ \\
\hline \multicolumn{7}{|l|}{ E-cigarette use N (\%) } \\
\hline No & $43006(62)$ & $1546(19)$ & $811(28)$ & $9312(45)$ & $1149(53)$ & $30118(85)$ \\
\hline Experimental use & 23079 (33) & $5062(62)$ & 1700 (59) & $10224(50)$ & $944(43)$ & $5149(14)$ \\
\hline Often use & $2608(3.8)$ & $1197(15)$ & 294 (10) & $900(4.4)$ & $51(2.3)$ & $166(0.5)$ \\
\hline Daily use & 755 (1.1) & $382(4.7)$ & $101(3.5)$ & $179(0.9)$ & $38(1.7)$ & $55(0.2)$ \\
\hline \multicolumn{7}{|l|}{ Snuff/chewing tobacco use N (\%) } \\
\hline No & 51915 (75) & $4370(54)$ & $1496(52)$ & $13007(63)$ & $1523(70)$ & 31519 (89) \\
\hline Experimental use ${ }^{\wedge}$ & $14905(22)$ & $3223(40)$ & $1181(41)$ & 6425 (31) & $555(26)$ & $3521(9.9)$ \\
\hline Often use & $1724(2.5)$ & $356(4.4)$ & $153(5.3)$ & 805 (3.9) & $57(2.6)$ & $353(1.0)$ \\
\hline Daily use & $613(0.9)$ & $120(1.5)$ & $57(2.0)$ & $273(1.3)$ & $30(1.4)$ & $133(0.4)$ \\
\hline \multicolumn{7}{|l|}{ Wish to quit smoking $N(\%)$} \\
\hline No & 13898 (45) & $1792(22)$ & 1064 (37) & $11042(55)$ & & \\
\hline Yes, but not planned & 12142 (39) & $4.932(60)$ & $1343(46)$ & $5867(29)$ & & \\
\hline Yes, within the next 6 months & $1241(4.0)$ & $788(9.6)$ & $159(5.5)$ & 294 (1.5) & & \\
\hline Yes, within the next month & 3754 (13) & 700 (8.5) & $335(12)$ & 2719 (14) & & \\
\hline
\end{tabular}


Figure 2. Prevalence (\%) of daily smoking (cigarettes or water pipe or e-cigarettes) among Danish high school students in the Danish National Youth Study $2014(n=70243)$

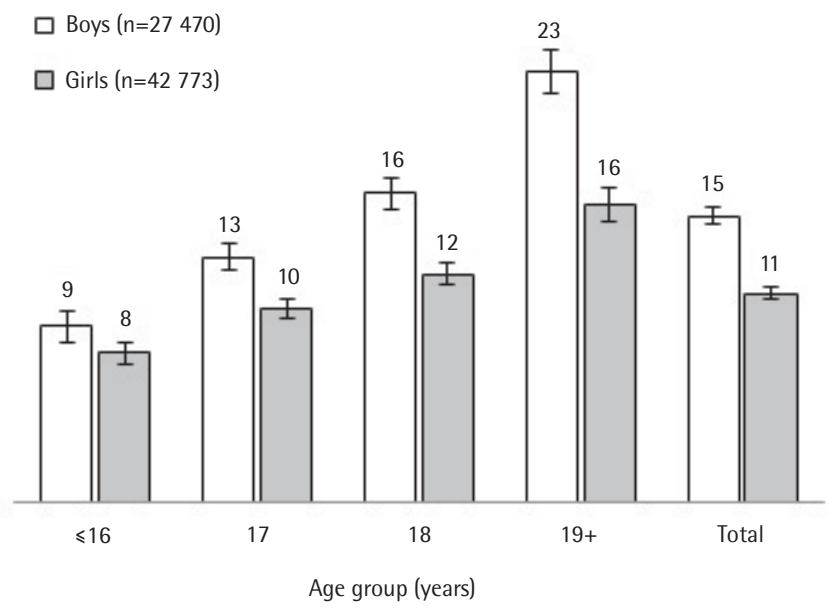

a combined influence of school and school class. As to the relative impact of school and school class, the school class was the most influential factor. For instance, 7\% of the variation in daily smoking could be ascribed to school-level whereas $12 \%$ could be ascribed to school class-level.

\section{Development since 1997}

Figure 3 shows the proportion of daily smokers, occasional smokers and non-smokers among highschool students in 1997 and 2014. Among girls, the proportion of daily smokers was lower in 2014 (11\%) than in $1997(16 \%)$, while it was roughly the same among boys. However, the proportion of occasional smokers was higher among both girls and boys in 2014 compared to 1997. The proportion of non-smokers was lower in 2014 (55\%) than in 1997 (63\%).

Table 3. Intra-class correlation coefficient (ICC) and 95\% confidence interval (CI) for measures of smoking, smokeless tobacco use, and wish to quit smoking

\begin{tabular}{|c|c|c|c|c|c|c|}
\hline & \multicolumn{2}{|c|}{ School } & \multicolumn{2}{|c|}{ Class } & \multirow{2}{*}{$\begin{array}{l}\text { School } \\
\text { ICC }\end{array}$} & \multirow{2}{*}{$\begin{array}{l}\text { Class } \\
\qquad 5^{\circ} \% \mathrm{OI}\end{array}$} \\
\hline & ICC & $95 \% \mathrm{CI}$ & ICC & $95^{\circ} \% \mathrm{CI}$ & & \\
\hline Daily smoker ( $n=70243)$ & 0.07 & $(0.05-0.09)$ & 0.12 & $(0.12-0.13)$ & 0.19 & $(0.17-0.21)$ \\
\hline Snuff/chewing tobacco use ( $\mathrm{n}=69$ 157) & 0.11 & $(0.08-0.14)$ & 0.17 & $(0.16-0.18)$ & 0.27 & $(0.24-0.31)$ \\
\hline Water pipe use $(\mathrm{n}=69965)$ & 0.04 & $(0.03-0.06)$ & 0.07 & $(0.07-0.08)$ & 0.12 & $(0.10-0.13)$ \\
\hline Electronic cigarette use ( $n=69$ 448) & 0.03 & $(0.02-0.05)$ & 0.13 & $(0.11-0.15)$ & 0.16 & $(0.14-0.18)$ \\
\hline Wish to quit smoking $(\mathrm{n}=31035)$ & 0.00 & $(0.00-0.01)$ & 0.02 & $(0.02-0.03)$ & 0.03 & $(0.02-0.04)$ \\
\hline
\end{tabular}

Adjusted for age, sex and study program.

Figure 3. Prevalence (in \%) of cigarette smoking in $1997(\mathrm{n}=24,465)$ and $2014(\mathrm{n}=70,243)$ in boys (left), girls (middle) and total (right)

$\square 1997(n=24465)$

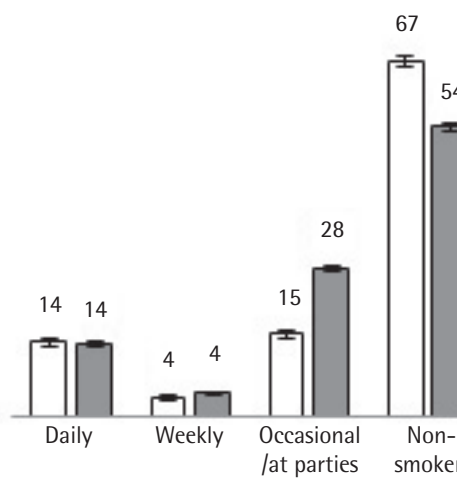

\section{DISCUSSION}

The present study investigated smoking and use of smokeless tobacco among 70243 Danish high-school students. A total of $12 \%$ reported daily cigarette smoking, and one in four (24\%) showed signs of $2014(\mathrm{n}=70243)$

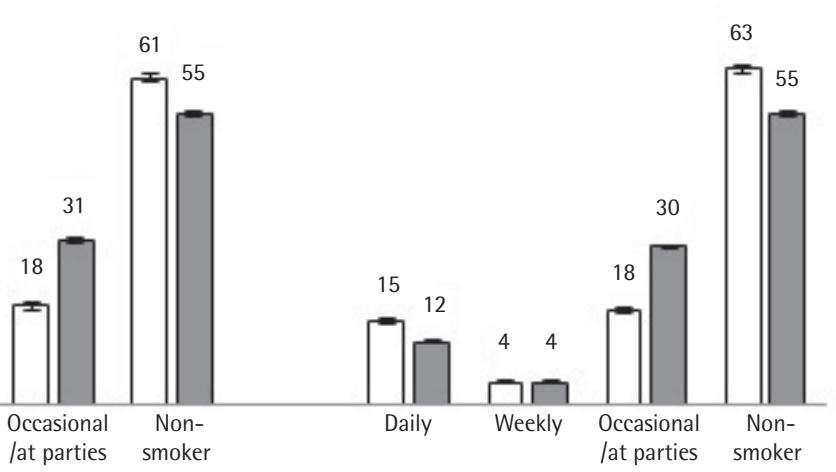

nicotine dependence. Waterpipe and e-cigarettes were also widely used among high-school students (daily or often used was $12 \%$ and $4.9 \%$, respectively), with the highest prevalence observed among daily smokers $(31 \%$ and $20 \%)$ and weekly smokers $(27 \%$ 
and 14\%). This supports the notion put forward by Maziak $^{3}$, that waterpipe use is an increasing epidemic that calls for political attention and more research on the health effects of its use. A total of $15 \%$ of the boys and $11 \%$ of the girls smoked either cigarettes, waterpipe or e-cigarettes daily.

The prevalence of smoking increased with age, and markedly so among boys than girls. Consistent with previous findings of school level variations in substance use, factors related to school and class environment accounted for a relatively large proportion of the variation in smoking behavior ${ }^{14}$. Class level variation in smoking behavior and tobacco use were consistently found to explain more than school level variation. This result indicates that factors associated with social dynamics and norms between students, may be more important for smoking behavior than local conditions, such as geography and neighbourhood socio-economy represented by the school level. School and class level variation in the students wishing to quit smoking was low, which indicates that the wish to quit smoking was consistently high across smokers in high schools. The prevalence of smoking was high among Danish high-school students and has virtually not changed since 1997.

A number of influential factors have changed from 1997 to 2014. Different types of smoking legislation have been introduced in Denmark between 1997 and 2014; the most comprehensive being The Smokefree Environment Act in 2007. However, compared to tobacco legislation in most other European countries, Danish national tobacco legislation is still lenient: The Tobacco Control Scale was constructed in 2006 with $^{25}$ the purpose of being able to characterize and compare tobacco control activity at the country level in Europe $^{24}$. In 2016, Denmark ranked 23 out of 35 countries on the Tobacco Control Scale ${ }^{25}$. For instance, smoking in bars is allowed in small-size establishments, and the price per package is low (approximately 5.5 Euros).

As demonstrated in our study, the prevalence of smoking in Danish high-school students was virtually unchanged from 1997 to 2014, especially if daily e-cigarette and waterpipe smoking is considered to be on par with cigarette smoking. Preventing smoking among children and adolescents is a vital public health objective and a prerequisite for reaching a tobacco endgame soon, thus this is a distressing result. A change, of course, could be accelerated by implementing interventions known to be effective, such as an increase in cigarette prices, which is known to be especially effective in young people ${ }^{26}$, and plain packaging. ${ }^{27}$

\section{Study strengths and limitations}

The large survey sample is one of the main strengths of this study. The study included an almost complete sample of Danish high-school students. Since all general high schools were invited and participation rates at all levels (school, class, student) were high $(87 \%, 96 \%, 85 \%)$, the study population is assumed to be representative of students in Danish high schools and the risk of selection bias is considered low. The low no-response rate led to almost intact units (schools and classes), which is particularly advantageous for multilevel modelling of clustering effects.

Young people outside the educational system, or students attending other secondary education, were not included in this study. High-school students may in fact have the lowest smoking prevalence among young people in Denmark, as 16-25 year old men and women have been found to have a daily smoking prevalence of $15.2 \%$ and $12.8 \%$, respectively, in a national representative study from $2013^{28}$, while vocational-school students have a daily smoking prevalence around $45 \%{ }^{29}$.

The study included a wide range of measures of tobacco use and smoking behavior, which made it possible to give a detailed description of tobacco use among Danish high-school students. Most smoking measures were taken from national and international surveys ${ }^{20,28,30}$ to make the results comparable. Some questions were developed specifically for the Danish National Youth Study 2014. The questions were developed in close collaboration with Danish researchers in the field. All measures of smoking and smokeless tobacco use were self-reported but were not biochemically validated. Smoking behavior may therefore be under-reported due to the need to give socially acceptable answers ${ }^{31}$. However, self-reported smoking has been found to have high validity in community studies ${ }^{31,32}$.

Furthermore, comparable measures in the 1997 survey made it possible to assess the chronological 
trend in smoking from 1997 to 2014. To give a more detailed picture of the trends in smoking behavior among high-school students it would have been preferable to have had more time points. However, the comparability, sample size and representativeness of the two surveys makes comparisons interesting, as an indication of time trends.

\section{CONCLUSIONS}

Daily cigarette smoking was highly prevalent among Danish high-school students and every fourth daily smoker showed sign of nicotine dependence. Generally, the prevalence of smoking among Danish high-school students has changed little since 1997. Alternative smoke and smokeless products, such as e-cigarettes, waterpipe, snuff and chewing tobacco, were also frequently used, especially among daily and occasional cigarette smokers. Factors related to school and class environment accounted for a large part of the variation in the student's smoking behavior. This finding combined with the agerelated increase in smoking during high school, calls for effective school-based smoking prevention interventions. Also, smoking cessation should be brought into focus in prevention activities, as a large proportion of these young smokers wished to quit smoking.

\section{REFERENCES}

1. Smoking prevalence and attributable disease burden in 195 countries and territories, 1990-2015: a systematic analysis from the Global Burden of Disease Study 2015. Lancet (London, England). 2017;389: 1885-906.

2. Lund I and Scheffels J. Adolescent tobacco use practices and user profiles in a mature Swedish moist snuff (snus) market: Results from a school-based crosssectional study. Scandinavian journal of public health. 2016;44(7):646-53. doi:10.1177/1403494816656093

3. Maziak W. Rise of waterpipe smoking. BMJ (Clinical research ed). 2015;(apr17 5)350: h1991. doi: 10.1136/bmj.h1991

4. Maziak W, Taleb ZB, Bahelah R, Islam F, Jaber R, Auf $\mathrm{R}$ et al. The global epidemiology of waterpipe smoking. Tobacco control. 2014;24(Suppl 1): i3-i12. doi: 10.1136/tobaccocontrol-2014-051903

5. Salloum RG, Thrasher JF, Getz KR, Barnett TE, Asfar T and Maziak W. Patterns of Waterpipe Tobacco Smoking Among U.S. Young Adults, 2013-2014. American journal of preventive medicine. 2017;52(4):507-12. doi: 10.1016/j.amepre.2016.10.015

6. Pisinger C and Døssing M. A systematic review of health effects of electronic cigarettes. Preventive medicine. 2014;69:248-60. doi:10.1016/j.ypmed.2014.10.009

7. Hajek P, Etter JF, Benowitz N, Eissenberg T and McRobbie H. Electronic cigarettes: review of use, content, safety, effects on smokers and potential for harm and benefit. Addiction. 2014;109(11):1801-10. doi:10.1111/add.12659

8. Levy DT1, Mumford EA, Cummings KM, Gilpin EA, Giovino G, Hyland A, et al. The relative risks of a lownitrosamine smokeless tobacco product compared with smoking cigarettes: estimates of a panel of experts. Cancer Epidemiol Biomarkers Prev. 2004 Dec;13(12):2035-42.

9. Soneji Samir, Barrington-Trimis Jessica L., Wills Thomas A., Leventhal Adam M., Unger Jennifer B., Gibson Laura A., et al. Association Between Initial Use of e-Cigarettes and Subsequent Cigarette Smoking Among Adolescents and Young Adults: A Systematic Review and Metaanalysis. JAMA pediatrics. 2017;171(8). doi: 10.1001/jamapediatrics.2017.1488

10. Jaber R, Madhivanan P, Veledar E, Khader Y, Mzayek $\mathrm{F}$ and Maziak W. Waterpipe a gateway to cigarette smoking initiation among adolescents in Irbid, Jordan: a longitudinal study. The international journal of tuberculosis and lung disease : the official journal of the International Union against Tuberculosis and Lung Disease. 2015;19(4):481-7. doi:10.5588/ijtld.14.0869

11. Sawyer SM, Afifi RA, Bearinger LH, Blakemore SJ, Dick B, Ezeh A C et al. Adolescence: a foundation for future health. Lancet. 2012;379 (9826):1630-40. doi:10.1016/s0140-6736(12)60072-5

12. Viner RM, Ozer EM, Denny S, Marmot M, Resnick M, Fatusi A et al. Adolescence and the social determinants of health. Lancet. $2012 ; 379$ (9826):1641-52. doi:10.1016/s0140-6736(12)60149-4

13. Crosnoe Robert, Johnson Monica Kirkpatrick. Research on adolescence in the twenty-first century. Annual Review of Sociology 2011;37(1): 439-60.

doi: 10.1146/annurev-soc-081309-150008

14. Costello MJ, Leatherdale ST, Ahmed R, Church DL and Cunningham JA. Co-morbid substance use behaviors among youth: any impact of school environment? Global health promotion. 2012; 19:(1)50-9. doi:10.1177/1757975911429873

15. U.S. Department of Health and Human Services PHS, Office of the Surgeon General. The Health Consequences of Smoking-50 Years of Progress. A Report of the Surgeon General. 2014.

16. Sowell ER, Peterson BS, Thompson PM, Welcome SE, Henkenius AL and Toga AW. Mapping cortical change across the human life span. Nature neuroscience. 2003;6(3): 309-15. doi:10.1038/nn1008

17. Giedd JN. Structural magnetic resonance imaging of the adolescent brain. Annals of the New York Academy of Sciences. 2004;1021(1):77-85. 
doi:10.1196/annals.1308.009

18. Kendler KS, Myers J, Damaj MI and Chen X. Early smoking onset and risk for subsequent nicotine dependence: a monozygotic co-twin control study. The American journal of psychiatry. 2013;170(4):408-13. doi:10.1176/appi.ajp.2012.12030321

19. Pisinger VSC, Mikkelsen SS, Bendtsen P, Egan KK and Tolstrup JS. The Danish National Youth Study 2014: Study design, population characteristics and nonresponse analysis. Scandinavian journal of public health. 2017. doi:10.1177/1403494817729283

20. Nielsen GA. Gymnasie- \& HF-elevers sundhedsvaner \& livsstil 1996-97. Copenhagen: DIKE 1998.

21. Heatherton TF, Kozlowski LT, Frecker RC and Fagerström KO. The Fagerström test for nicotine dependence: a revision of the Fagerstrom Tolerance Questionnaire. Addiction. 1991;86(9):1119-27. doi:10.1111/j.1360-0443.1991.tb01879.x

22. Jensen VM and Rasmussen AW. Danish education registers. Scandinavian journal of public health. 2011;39(suppl 7):91-4. doi: 10.1177/1403494810394715

23. Merlo J, Chaix B, Ohlsson H, Beckman A, Johnell K, Hjerpe P et al. A brief conceptual tutorial of multilevel analysis in social epidemiology: using measures of clustering in multilevel logistic regression to investigate contextual phenomena. Journal of epidemiology and community health. 2006;60(40):290-7.

doi:10.1136/jech.2004.029454

24. Joossens L and Raw M. The Tobacco Control Scale: a new scale to measure country activity. Tobacco control. 2006;15(3): 247-53. doi:10.1136/tc.2005.015347

25. Joossens LR, M. The Tobacco Control Scale 2016 in Europe. In: Leagues AoEC, (ed.). Belgium; 2017.

26. Guindon GE. The impact of tobacco prices on smoking onset: a methodological review. Tobacco control. 2014;23(2): e5. doi:10.1136/tobaccocontrol-2012-050496

27. Hughes N, Arora M and Grills N. Perceptions and impact of plain packaging of tobacco products in low and middle income countries, middle to upper income countries and low-income settings in high-income countries: a systematic review of the literature. BMJ open. 2016;6 (3): e010391. doi:10.1136/bmjopen-2015-010391

28. Christensen AI, Davidsen M, Ekholm O, Pedersen PV and Juel K. Danes health: The national health profil 2013. [Danskernes sundhed: Den nationale sundhedsprofil 2013]. 2014.

29. Andersen S, Rod MH, Ersbøll AK, Stock C, Johansen C, Holmberg $\mathrm{T}$ et al. Effects of a settings-based intervention to promote student wellbeing and reduce smoking in vocational schools: A non-randomized controlled study. Social Science \& Medicine. 2016;161: 195-203. doi:10.1016/j.socscimed.2016.06.012

30. Inchley J and Currie D. Growing up unequal: gender and socioeconomic differences in young people's health and well-being. Health Behaviour in School-aged Children
(HBSC) study: international report from the. 2013; 2014.

31. Gorber SC, Schofield-Hurwitz S, Hardt J, Levasseur Gv and Tremblay M. The accuracy of self-reported smoking: A systematic review of the relationship between selfreported and cotinine-assessed smoking status. Nicotine \& Tobacco Research. 2009;11(1):12-24. doi: 10.1093/ $\mathrm{ntr} / \mathrm{ntn} 010$.

32. Vartiainen E, Seppälä T, Lillsunde P and Puska P. Validation of self reported smoking by serum cotinine measurement in a community-based study. Journal of Epidemiology \& Community Health. 2002;56(3):16770.doi: 10.1136/jech.56.3.167
CONFLICTS OF INTEREST Authors have completed and submitted the ICMJE Form for Disclosure of Potential Conflicts of Interest and none was reported.

\section{FUNDING}

There was no source of funding for this research.

PROVENANCE AND PEER REVIEW

Not commissioned; externally peer reviewed 